\title{
Degeneration of the olfactory epithelium in the Anguilid eels by hormone treatment
}

\author{
Ching Fui Fui' ${ }^{*}$, Gunzo Kawamura1, Kazuhiko Anraku², Bensan Bin Alex ${ }^{1}$, Nabilah Zieha Binti Sikh \\ Mohamad and Shigeharu Senoo ${ }^{1,3}$ \\ ${ }^{1}$ Borneo Marine Research Institute, Universiti Malaysia Sabah, Jalan UMS, 88400 Kota Kinabalu, Sabah, Malaysia \\ 2 Faculty of Fisheries, Kagoshima University, Shimoarata 4-50-20, Kagoshima, Japan \\ ${ }^{3}$ Aquaculture Technology and Production Center, Kindai Univerisity, Shirahama 649-2211, Wakayama, Japan
}

${ }^{*}$ Corresponding author: cfuifui@ums.edu.my

\begin{abstract}
While the olfactory cue hypothesis has been proposed for spawning migration of silver eels, it has been shown that olfactory cells and associated mucus cells degenerate in male and female eels after hormonally induced sexual maturation. However, the degeneration of the olfactory organ could be a real event in the sequence of maturation, or may be an unnatural side effect of the hormone treatment itself. We morphologically and histologically examined the olfactory rosettes of hormone-untreated and hormone-treated (mixture of $\mathrm{hCG}$ and PG) giant mottled eel (Anguilla marmorata) and Japanese eel (A. japonica). The olfactory rosette from all the hormone-treated specimens significantly degenerated at various degeneration levels even in sexually immature specimens, indicating the side effect of the hormone-treatment. However, a sexually immature non-hormone treated female A. marmorata ( $87.4 \mathrm{~cm}$ TL, $199.4 \mathrm{~g} \mathrm{BW}$, at less advanced maturity) had slightly degenerated olfactory rosette. Further studies should focus on conducting natural degeneration of the olfactory rosette during the sexual maturation in tropical eels.
\end{abstract}

Keywords: Olfactory organ, Tropical eel, Spawning migration

\section{Introduction}

Freshwater eels are catadromous species whose life cycle is considered unique due to the amplitude of the spawning migration. They breed in oceanic water, migrate long distances to the coasts and into fresh water, and return to the breeding grounds years later. Eels spawn in the open ocean; the eggs hatch into transparent, leaf-like larvae called leptocephali that drift with the ocean currents. At about 5 to $6 \mathrm{~cm}$ in total length, the leptocephali metamorphose into transparent cylindrical fish known as glass eels, which migrate to coastal waters. The juveniles grow through a yellow phase, then become adults (silver phase) that migrate back to the spawning ground in the North Equatorial Current for the giant mottled eel (A. marmorata) and the Japanese eel (A. japonica) (Arai, 2014). The final migration ends in death of adults after spawning.

How eels find their way during the long-distance migration back to the spawning ground is still a puzzle, despite much quantitative research that has been done. It has been postulated that eels orient by sensing information from the earth's magnetic field (McCleave and Power, 1978; Souza et al., 1988; Tesch and Rohlf, 2003). It has been demonstrated that $A$. japonica is already magnetosensitive at the glass eel phase (Nishi et al., 2004; Nishi and Kawamura, 2005) and possesses magnetosensitive cells in or around the nose (Nishi et al., 2005). Recently Nishi et al. (2018) reported behavioural evidence for the use of geomagnetic cue in A. japonica glass eel orientation in the arena; the glass eels significantly preferred a southerly direction in the local geomagnetic field, while biased orientation of this species disappeared in the null horizontal component of the geomagnetic field. Thus, $A$. japonica could use the geomagnetic field as the directional guide for its longdistance migration.

On the other hand, olfactory cue hypothesis has been proposed for spawning migration of silver eels. Several studies have demonstrated the importance of olfaction rather than magnetosense in the migration of $A$. anguilla (Westin, 1990) and $A$. rostrata (Barbin et al., 1998); the group which had been made anosmic by injection of hot petroleum jelly into their nasal cavity behaved differently from the control group - irregular swimming, slower speed, and lack of common direction, or spending more time in the estuary. On the other hand, eels serving the control set moved upstream and downstream with the tides. However, the anosmia technique damages the magnetosensitive organ located around the nares. Eels were rendered anosmic by filling both nares with petroleum jelly; control group eels were not treated. Nishi et al. (2005) reported the side-effect of anosmia (induced by injection of hot white petroleum jelly into the nasal cavity) on the magnetosensitivity of $A$. japonica. Tesch (2003) noted that the eel's extremely sensitive nose is out of the question for orientation to a compass course or to guide the eel across greater distances.

Olfaction is well developed in eels; however, olfactory cue hypothesis is unlikely in the light of previous evidences. Pankhurst and Lythgoe (1983) and Sorensen and Pankhurst (1988) showed that olfactory cells and associated mucus 
cells degenerate in male and female eels after hormonally induced sexual maturation. This suggests that olfaction will be less important during the marine migration phase of the life cycle than during the freshwater phase when eels are still feeding. They noted, however, that the degeneration of the olfactory organ may be a real event in the sequence of maturation, or may be an unnatural side effect of the hormone treatment itself. Thus, the olfactory hypothesis has remained a controversial topic.

The objective of this study was to determine the effect of hormone treatment on morphology and histology of the olfactory rosettes in Anguilid eels.

\section{Materials and Methods}

Eel culture project started in the fish hatchery of Borneo Marine Research Institute (BMRI), University Malaysia Sabah, in 2017. Glass eel (A. marmorata) from Indonesia and $A$. japonica from Japan were reared to adult stage in tanks. The artificial maturation was conducted with hormone treatment. Sexual maturation was induced by intramuscular injection of a mixture of hormones (human chorionic gonadotropin hCG and salmon pituitary extract SPE) in a dose of $0.1 \mathrm{~mL} 100 \mathrm{~g}^{-1}$ at five days interval (Kagawa et al., 2005). Eels were anaesthetized in $0.05 \%$ MS222 before this treatment. African night crawler and Squid were offered once daily at noon on alternate days.

Hormone-treated eel (A. marmorata, $35.5-74.5 \mathrm{~cm}$ in total length; $A$. japonica, 41.3-56.7 cm) were obtained from groups that accidentally died and were measured for total length, body weight and gonad weight (when possible), and the heads of relatively fresh specimens were preserved in Bouin's solution for $24 \mathrm{~h}$ and transferred to $70 \%$ ethanol. While the exact time of death was unknown, it might be less than 10 h. A wild captured A. marmorata (total length 87.4 $\mathrm{cm}$, body weight $199.4 \mathrm{~g}$ ) (Figure 1) was obtained from a local market, Sabah. The head of this specimen was preserved in Bouin's solution $4 \mathrm{~h}$ after it died. The ovary of this specimen was much smaller than that of ocean-migrating $A$. japonica (68.1 cm TL) as reported by Matsuya et al. (2015). Therefore, the wild captured $A$. marmorata was considered to be at a less advanced stage of maturation. Bouin's solutiontreated five heads of non-hormone treated $A$. japonica yellow eels (47.7-56.3 cm) were obtained from the Faculty of Fisheries, Kagoshima University, Japan.
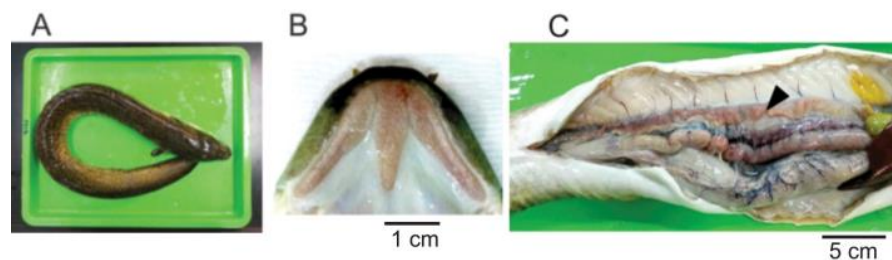

Figure 1. Anguilla marmorata. Wild captured specimen (total length $87.4 \mathrm{~cm}$, body weight $199.4 \mathrm{~g}$ ) (A), teeth pattern from the upper jaw of this specimen (B), ovary at less advanced maturation shown by an arrowhead (C).
The nasal capsules were dissected, the olfactory rosettes were exposed and photographed (YS 100, Nikon Corporation, Tokyo, Japan) and measured for length and width, and the number of the olfactory lamellae was counted. The olfactory rosettes were then removed and dehydrated using ethanol, embedded in paraffin and sagittally sectioned ( $6 \mu \mathrm{m}$ thick). Sections were stained with haematoxylin and eosin. Light microscopy was done with a NIKON Eclipse E600, YS 100, Nikon Corporation, Tokyo, Japan and NIKON Eclipse 801, YS 100, Nikon Corporation, Tokyo, Japan.

\section{Results and Discussion}

\section{Morphology of olfactory rosette}

In non-hormone treated eel, the olfactory rosettes were ovalshaped and the olfactory lamellae were radially arranged, and all of them were countable (Figures 2 and 5, Table 1). In hormone-treated eels, all the olfactory rosettes were deformed (Figures 2 and 5). In the wild captured $A$. marmorata, the olfactory rosettes lacked several olfactory lamellae and occupied 2/3 of the olfactory cavity (Figure 2A). The size of the olfactory rosette increased lineally with total length as shown in Figure 3. The correlation between the olfactory rosette length and total length of $A$. marmorata of wild captured specimen formed an apparent outlier showing the significant deformation of the olfactory rosette in this specimen.

Table 1. Number of olfactory lamellae and size of olfactory rosettes of hormone-treated and non-hormone treated

\section{A. marmorata and $A$. japonica.}

\begin{tabular}{|c|c|c|c|c|c|c|c|}
\hline \multirow[t]{2}{*}{ Species } & \multicolumn{2}{|c|}{ No. of lamellae } & \multicolumn{2}{|c|}{$\begin{array}{c}\text { Length of } \\
\text { olfactory } \\
\text { rosette }(\mathrm{mm})\end{array}$} & \multicolumn{2}{|c|}{$\begin{array}{c}\text { Width of } \\
\text { olfactory } \\
\text { rosette }(\mathrm{mm})\end{array}$} & \multirow[t]{2}{*}{ Remrks } \\
\hline & Right & Left & Right & Left & Right & Left & \\
\hline \multirow[t]{10}{*}{ A. marmorata } & 27 & 40 & 5.24 & 5.25 & 1.79 & 1.98 & Hormone-treated \\
\hline & 69 & 54 & 4.42 & 4.74 & 1.81 & 2.11 & Ditto \\
\hline & - & - & 4.74 & 4.89 & 1.96 & 2.15 & Ditto, difficult to cound \\
\hline & 42 & 38 & 3.14 & 3.09 & 1.02 & 1.00 & Non-hormon treated \\
\hline & 42 & 40 & 4.55 & 4.79 & 1.93 & 2.14 & Ditto \\
\hline & 63 & 59 & 5.01 & 4.87 & 2.13 & 1.95 & Ditto \\
\hline & 47 & 49 & 4.8 & 4.91 & 1.50 & 1.58 & Ditto \\
\hline & 53 & 50 & 6.89 & 6.57 & 1.96 & 1.85 & Ditto \\
\hline & 51 & 56 & 5.29 & 5.14 & 1.90 & 1.77 & Ditto \\
\hline & 44 & 43 & 3.49 & 3.55 & 1.40 & 1.58 & Ditto \\
\hline \multirow{9}{*}{ A. japonica } & - & - & - & - & - & - & Hormone-treated, difficult to count \\
\hline & - & - & - & - & - & - & Ditto \\
\hline & - & - & 5.81 & 5.68 & 2.15 & 2.12 & Ditto \\
\hline & - & 60 & 5.72 & 5.76 & 2.85 & 3.05 & Ditto \\
\hline & 62 & 64 & 3.85 & 4.77 & 1.96 & 2.12 & Non-hormon treated, from Japan \\
\hline & 63 & 66 & 4.89 & 4.97 & 1.96 & 2.11 & Ditto \\
\hline & 67 & 70 & 5.20 & 5.25 & 2.13 & 2.15 & Ditto \\
\hline & 65 & 66 & 5.17 & 4.83 & 1.89 & 2.10 & Ditto \\
\hline & 69 & 66 & 5.14 & 5.12 & 1.97 & 1.83 & Ditto \\
\hline
\end{tabular}

\section{Histology of olfactory epithelium}

In the non-hormone treated $A$. japonica, the olfactory epithelium consisted of olfactory hairs, nuclei of receptor and basal cells, and large mucous cells which were clearly observable (Figure 6A). It is a common histological structure of the olfactory epithelium of teleost fishes. In the hormonetreated eels, the olfactory epithelium significantly degenerated and the olfactory epithelium cells were not identified (Figures 4 and 6). 

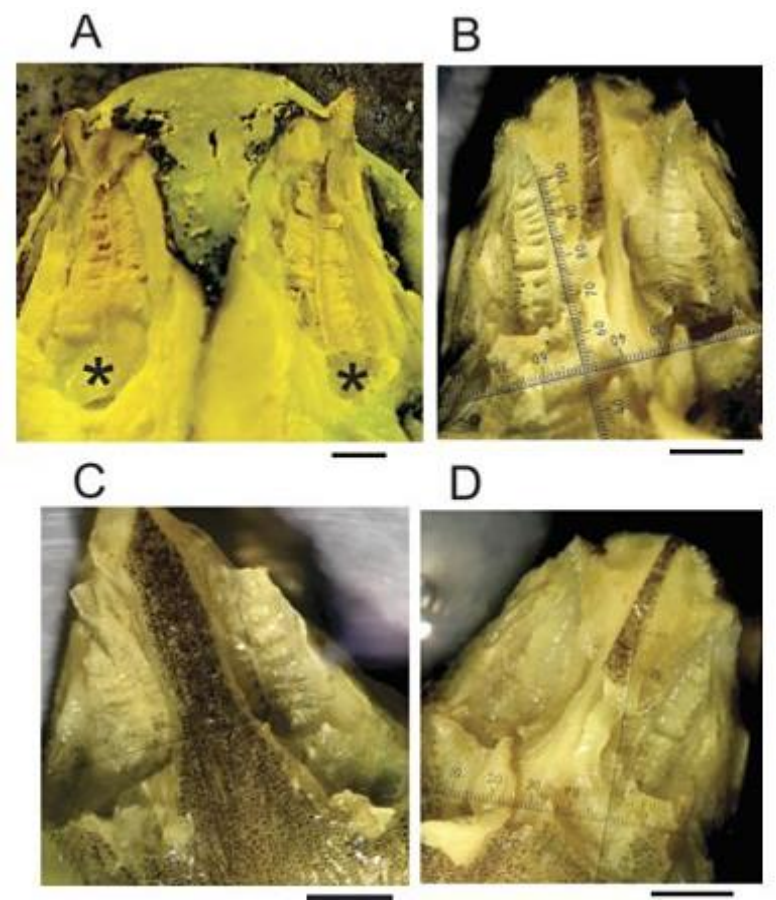

Figure 2. Anguilla marmorata. Dorsal view of the olfactory rosettes of non-hormone treated wild captured specimen $(A)$, and hormone treated three farmed specimens (B, C, D). * denotes lack of olfactory lamellae (A). Scale bar, $2 \mathrm{~mm}$.

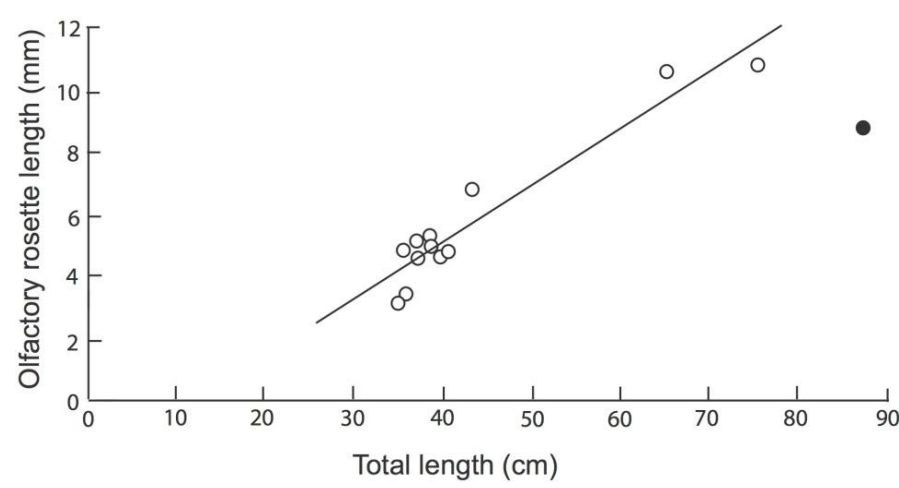

Figure 3. Anguilla marmorata. Correlation between right olfactory rosette length and total length of $A$. marmorata. Black circle (outlier) denotes wild captured $A$. marmorata. The regression line is expressed as $Y=0.182 X-2.098(\mathrm{n}=12$, $r=0.956, P<0.01)$. The outlier is not included in the calculation.
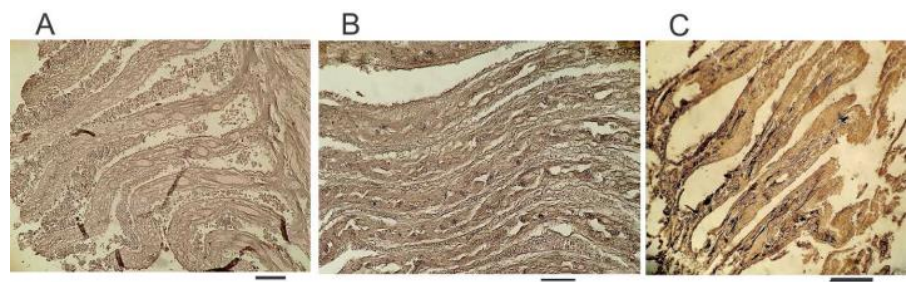

Figure 4. Anguilla marmorata. Light micrographs of sagittal sections of olfactory rosettes of a non-hormone treated wild captured specimen (A) and two hormone-treated sexually maturing farmed specimens (B, C). $8 \mu \mathrm{m}$ thick, HE stained.
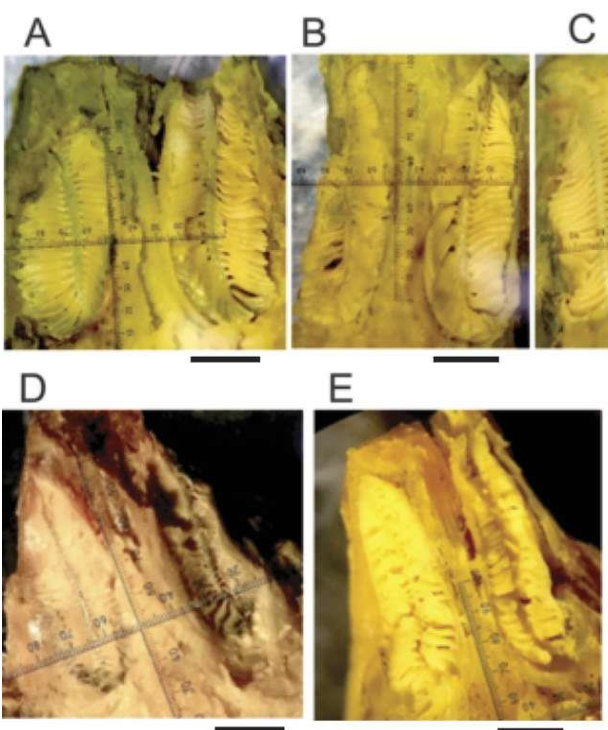

$\mathrm{F}$

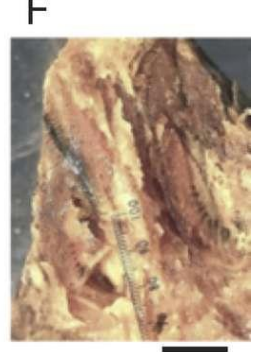

Figure 5. Anguilla japonica. Dorsal view of the olfactory rosettes of three non-hormone treated specimens $(A, B, C)$ and hormone-treated specimens (D, E, F). Scale bar, $2 \mathrm{~mm}$.
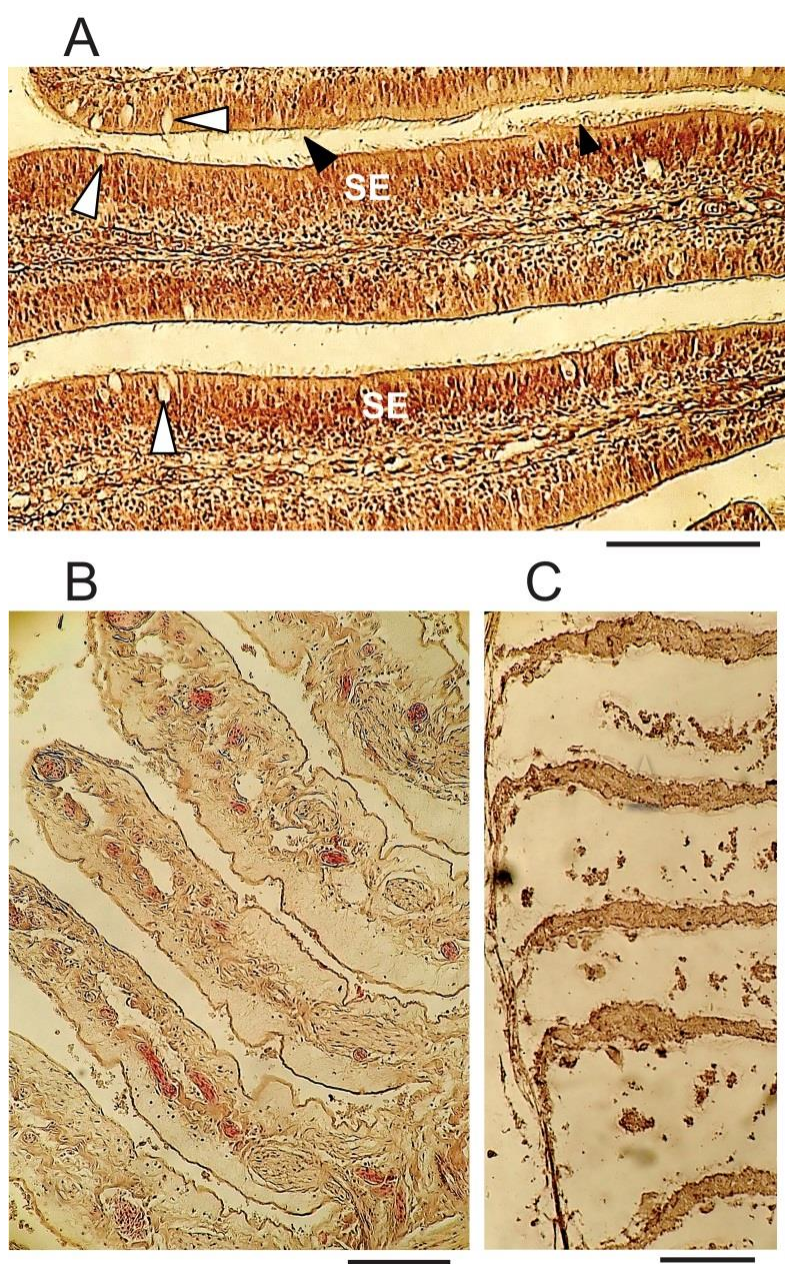

\section{C}

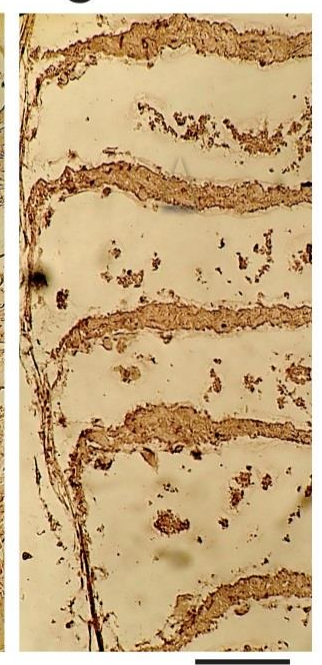

Figure 6. Anguilla japonica. Light micrographs of sagittal sections of olfactory rosettes of a hormone-untreated specimen (A) and two hormone-treated specimens (B, C). Mucous cells are shown by white arrowheads, olfactory hairs are shown by black arrowheads. $8 \mu \mathrm{m}$ thick, HE stained. Scale bar, $100 \mu \mathrm{m}$. 
The present study clearly showed the degeneration of the olfactory epithelium in the hormone-treated $A$. marmorata and $A$. japonica. The deformation of the olfactory rosette and the degeneration of the olfactory epithelium were evident in the wild captured large $A$. marmorata $(87.4 \mathrm{~cm} \mathrm{TL})$. Thus, the degeneration of the olfactory epithelium is evident in the large but immature tropical eel.

The natural generation of the olfactory epithelium in mature eel might be possible. Mature eels do not feed and are believed not to rely on the olfactory organ during the migration (Tesch, 2003). Experiments in which eels with blocked nasal cavities were transported from one North Sea coastal area to another, showed that such eels display the same homing trend as control eels (Tesch and Rohlf, 2003). Similar experiments conducted in the Bay of Gdansk exhibited no evidence of an olfactory orientation (Karlsson, 1984).

The degeneration of olfactory rosette at maturation is possible in naturally matured Anguilla eels. The degeneration of the olfactory epithelium can be either, a natural process with somatic growth of the eels, or the artifact of hormone treatment. If the natural degeneration takes place at maturation, the dependence on the olfaction during the spawning migration of Anguilla spp. is doubtful.

Because the olfactory rosette samples of $A$. marmorata were preserved in Bouin's solution several hours after the death of the fish (maximum $10 \mathrm{~h}$ in farmed $A$. marmorata and $4 \mathrm{~h}$ in wild specimen), the possibility of the post-mortal degeneration of the olfactory rosette could not be ruled out. However, the degeneration of the olfactory rosette was quite serious; loss of several olfactory lamellae and complete degeneration of the olfactory lamella cells. A natural degeneration process caused by cell death within $4 \mathrm{~h}$ or $10 \mathrm{~h}$ is doubtful. The possibility of natural degeneration of the olfactory rosette with somatic growth and maturation in tropical eels should be further investigated.

\section{References}

Arai, T. (2014). Do we protect freshwater eels or do we drive them to extinction? SpringerPlus 3, 534.

Barbin, G.P., Parker, S.J. \& McCleave, J.D. (1998). Olfactory clues play a critical role in the estuarine migration of silver-phase American eels. Environmental Biology of Fishes 53, 283-291.

Kagawa, H., Tanaka, H., Ohta, H., Umuma, T. \& Nomura, K. (2005). The first success of gglass eel production in the world: basic biology on fish reproduction advances new applied technology in aquaculture. Fish Physiology and Biochemistry 31, 193-199.

Karlsson, L. (1984). Migration of European silver eels, Anguilla anguilla. PhD. Thesis, Uppsala University, Uppsala, 745 pp.

Matsuya, N., Nagihara, S., Wada, T., Ijiri, S. \& Adachi, S. (2015). Morphological and physiological characteristics of an ocean-migrating Japanese eel Anguilla japonica off Fukuoka, Japan. Coastal Marine Science 38, 8-11.

McCleave, J. D. \& Power, J. H. (1978). Influence of weak electric and magnetic fields onturning behavior in elvers of the American eel Anguilla rostrata. Marine Biology 46, 29-34.
Nishi, T., Kawamura, G. \& Matsumoto, K. (2004). Magnetic sense in the Japanese eel Anguilla japonica as determined by conditioning and electrocardiography. Journal of Experimental Biology 207, 2965-2970.

Nishi, T. \& Kawamura, G. (2005). Anguilla japonica is already magnetosensitive at the glass eel phase. Journal of Fish Biology 67, 12131224 .

Nishi, T., Kawamura, G. \& Sannomiya, S. (2005). Anosmic Japanese eel Anguilla japonica can no longer detect magnetic fields. Fisheries Science 71, 101-106.

Nishi, T., Archdale, M.V. \& Kawamura, G. (2018). Behavioural evidence for the use of geomagnetic cue in Japanese glass eel Anguilla japonica orientation. Ichthyological Research 65, 161-164.

Pankhurst, N.W. \& Lythgoe, J.N. (1983). Changes in vision and olfaction during sexual maturation in the European eel Anguilla anguilla (L.). Journal of Fish Biology 23, 229-240.

Sorensen, P.W. \& Pankhurst, N.W. (1988). Histological changes in the gonad, skin, intestine and olfactory epithelium of artificially-matured male American eels, Anguilla rostrata (LeSueur). Journal of Fish Biology 32, 297-307.

Souza, J.J., Poluhowich, J.J. \& Guerra, R.J. (1988). Orientation responses of American eels, Anguilla rostrata, to varying magnetic fields. Comparative Biochemical Physiology 90A, 57-61.

Tesch, F.W. (2003). The Eel. Blakcwell Science Ltd., Oxford, UK.

Tesch, F.W. \& Rohlf, N. (2003). Migration from continental waters to the spawning grounds. In: Eel Biology (K. Aida, K. Tsukamoto \& K. Yamauchi, eds), pp. 223-234. Springer, Tokyo, Berlin, New York, London.

Westin, L. (1990) Orientation mechanisms in migrating European silver eel (Anguilla anguilla): temperature and olfaction. Marine Biology 106, 175-179. 